\title{
CASE STUDY OF THE TENSOR ANALYSIS OF GROUND DEFORMATIONS EVALUATED FROM GEODETIC MEASUREMENTS IN A LANDSLIDE AREA
}

\author{
Anna SZAFARCZYK and Rafał GAWALKIEWICZ
}

AGH University of Science and Technology, 30 Mickiewicza Av, 30-059 Krakow, Poland

*Corresponding author's e-mail: szafarcz@agh.edu.pl

\begin{tabular}{l} 
ARTICLE INFO \\
\hline Article history: \\
Received 19 October 2015 \\
Accepted 24 January 2016 \\
Available online 17 February 2016 \\
\hline
\end{tabular}

Keywords:

Landslide

Strain tensor

Geodetic measurements

\begin{abstract}
The series of geodetic measurements made in the area affected by deformations allows us to mark deformation indicators, the most important of which is, for the majority of constructions, horizontal strain. The strains can be horizontal, tensile or compressive.

Tensile strains cause the most serious damage in apartment buildings making fissures, cracks and - in extreme cases - even construction catastrophe. Depending on the accepted surveying technology, it is possible to determine the values of strains with smaller or greater accuracy.

The article presents the method and results of the measurement of the deformation in the fragments of a landslide (landslide of a natural slope in Milowka and landslide of the open cast mine Bełchatów). The surveying points were stabilized in the form of the measurement network called rectangular geodetic rosette. Based on the GPS measurement of the rosettes horizontal deformations on the directions of the stabilized sides were made. In the further stage the components of the surface strain tensor were marked, which made it possible to determine the direction and values of the extreme deformations.
\end{abstract}

\section{INTRODUCTION}

Surface mass movements, commonly called landslides have changeable dynamics (Teza et al., 2008; Dong et al., 2009; Yenes et al., 2009; Stumpf et al., 2013; Kostić et al., 2014; Prokešova et al., 2010; Szafarczyk et al., 2013). They become active due to natural causes, but can be also caused by human activities. A particularly important aspect of studying landslides is their impact on the objects of human activities and on the engineering and geological conditions. To achieve this, in the areas of landslide geodetic measurements are carried out with the use of different technologies and instruments (Wasowski and Bovenga, 2015; Ramesh, 2014; Gili et al., 2000; Zhu et al. 2011; Ćmielewski, 2013; Lenda et al., 2016). The results of the carried out measurements are used not only in the description of the phenomenon itself, but also give base for the assessment of the threat to buildings in the areas affected by deformations.

In the literature different landslide classifications can be found. According to Varnes (1978) and Cruden and Varnes (1996) the main criteria of the division are: the type of movement (falls, topples, slides, spreads, flows) and the type of the transported material (rock, debris, Earth). Classification by Savarensky (1981) is based on the features of the land sliding process mechanism, represented by the position of the displacement of the surface in relation to the structure of the rocks the landslide slope consists of. All landslides are divided into three classes: asequent, consequent and insequent. Pavlov's classification (Pavlov, 1968) covers all landslides which are divided into two classes on the basis of shear force direction in relation to landslide slope: delapsive landslides and detrusive landslides. Sharpe (1938) introduced a tri-dimensional classification system recognizing the type of movement, material and movement velocity. He also coined (presumably) the important terms of the debris flow (channelled), debris avalanche (open-slope), and earth flow.

Usually, for the description of the kinematics of surface mass movements, the values of the horizontal component of the dislocation vector and the value of the dislocations (Wang and Lin, 2011; Okamoto et al., 2004; McColl, 2015) is applied. These data sufficiently inform about the activity of the landslide or the lack of such activity. Considering the problem of landslide from the point of view of the threat to the buildings and infrastructure, the most significant deformation indicator is linear strain, especially linear tensile strain causing damage such as fissures and cracks.

\section{DETERMINING THE STRAIN TENSOR BASED ON THE RESULTS OF GEODETIC MEASUREMENTS}

Theoretic bases to determine deformations result from the elasticity theories. In a classical elasticity theory, some assumptions are made to simplify the problem. First of all it is assumed that all the 
a)

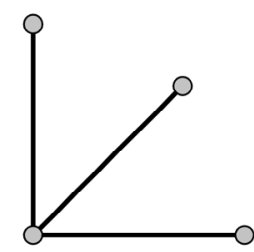

b)

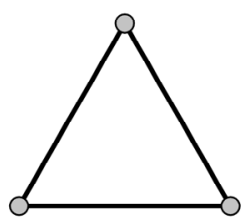

c)

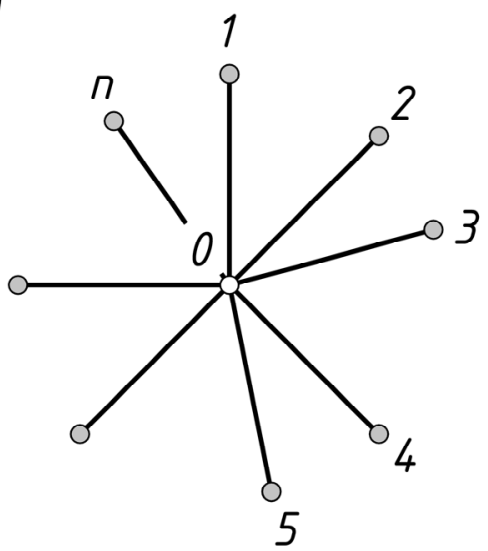

Fig. 1 The types of geodetic measurement rosettes:

a) rectangular rosette, b) triangular rosette c) rosette with a central point.

occurring dislocations and deformations are very small (Barber, 2002). It is also assumed that in an infinitely small environment of the point deformations have a linear character (Sokolnikoff, 1946) and that functions defining stress, dislocations and strains are continuous and differentiable. Among the five available in literature definitions of linear strain in the practice of surveying, the linear strain $\mathcal{E}$ in the Cauchy's definition is applied (Hjelmstad, 2005), according to the formula:

$\varepsilon=\frac{l-l_{0}}{l_{0}}$

where:

$l_{0}$ - length of the section in the initial measurement,

$l$ - length of the section after deformation.

The value of the calculated linear strains, determined based on the formula (1) refer only to concrete sides, for which they were determined. The knowledge of strain in any direction coming out of a given point (i.e. the knowledge of the components of the deformation tensor) is possible, if the minimum values of three linear strains are determined with the azimuths of their occurrence. This is implemented by making the measurement on the sides of so-called geodetic rosettes of different shape (Fig. 1).

These constructions are successfully applied in various geodetic measurements (Hejmanowski, 2005; Kontny et al., 2014; Kwinta, 2012; Szafarczyk, 2013; Pielok and Szafarczyk, 2004).

For each rosette the system of equations:

$\varepsilon_{i}=\varepsilon_{11} \cos ^{2} \varphi_{i}+2 \varepsilon_{12} \cos \varphi_{i} \sin \varphi_{i}+\varepsilon_{22} \sin ^{2} \varphi_{i}$

where:

$\varepsilon_{i}$ - linear strain on the side $i$,

$\phi_{i}$ - azimuth of the side $i$,

$\varepsilon_{11}, \varepsilon_{12}, \varepsilon_{22}$ - strain tensor components is formulated and solved. A solution to the system above is given by the strain tensor components.

The tensor of the state of strain in the matrix form is presented in the following way (Lebedev, 2010):

$\left\|\begin{array}{ll}\mathcal{E}_{11} & \varepsilon_{12} \\ \mathcal{E}_{21} & \varepsilon_{22}\end{array}\right\|$

Its components on the main diagonal: $\varepsilon_{11}=\frac{\partial u_{x}}{\partial x}, \varepsilon_{22}=\frac{\partial u_{y}}{\partial y}$ are interpreted as strains in the axis of the accepted system of coordinates, and the components beyond axis $\varepsilon_{12}=\varepsilon_{21}=\frac{1}{2}\left(\frac{\partial u_{y}}{\partial x}+\frac{\partial u_{x}}{\partial y}\right)$ are interpreted as dilatational strains.

In the space there are three mutually perpendicular directions, where the strains achieve extreme values $\varepsilon_{\max }, \varepsilon_{\min }$ and are called main strains, defined according to the relationship (Hill, 1950):

$\left.\begin{array}{l}\varepsilon_{\max } \\ \varepsilon_{\min }\end{array}\right\}=\frac{\varepsilon_{11}+\varepsilon_{22}}{2} \pm \frac{1}{2}\left[\left(\varepsilon_{11}-\varepsilon_{22}\right)^{2}+4 \varepsilon_{12}^{2}\right]^{1}$

with the angle $\beta$ between the direction of the occurring of maximal strain $\varepsilon_{\max }$, and the axis $x$ of the system of coordinates:

$\beta=\frac{1}{2} \operatorname{arctg} \frac{2 \varepsilon_{12}}{\varepsilon_{11}-\varepsilon_{22}}$

and the value of the dilatational strain $\gamma_{\text {ekstr }}$ :

$\gamma_{e k s t r}=\varepsilon_{\max }-\varepsilon_{\min }= \pm\left[\left(\varepsilon_{11}-\varepsilon_{22}\right)^{2}+4 \varepsilon_{12}^{2}\right]^{\frac{1}{2}}$ 
Triangular geodetic rosettes constructed on the network of the existing geodetic points were applied to the definition of the state of the surface deformation of two landslides varying in the degree of the activity and the origin.

\section{THE LANDSLIDE OF A NATURAL SLOPE IN MILÓWKA}

The landslide of a natural slope of the mount of Prusów in Milówka (Poland, Silesian Voivodeship, Żywiec District) became active in May 2010 after heavy rains. Mass movements covered the part of the slope between the ordinate $720 \mathrm{~m}$ a.s.l. and the bottom of the valley (600 $\mathrm{m}$ a.s.1.). The formed main scarp was from 4 to $12 \mathrm{~m}$ high and the slope was about $35^{\circ}$. The morphometric parameters of the landslide are presented in Table 1.

Table 1 Morphometric parameters of the landslide in Milówka.

\begin{tabular}{lr}
\hline Parameter & Value \\
\hline Area [ha] & 12 \\
Length [m] & 470 \\
Width [m] & 276 \\
Maximum height [m above sea level] & 715 \\
Minimum height [m above sea level] & 598 \\
Inclination $\left[^{\circ}\right.$ ] & 25 \\
Azimuth $\left[{ }^{\circ}\right.$ ] & 170 \\
\hline
\end{tabular}

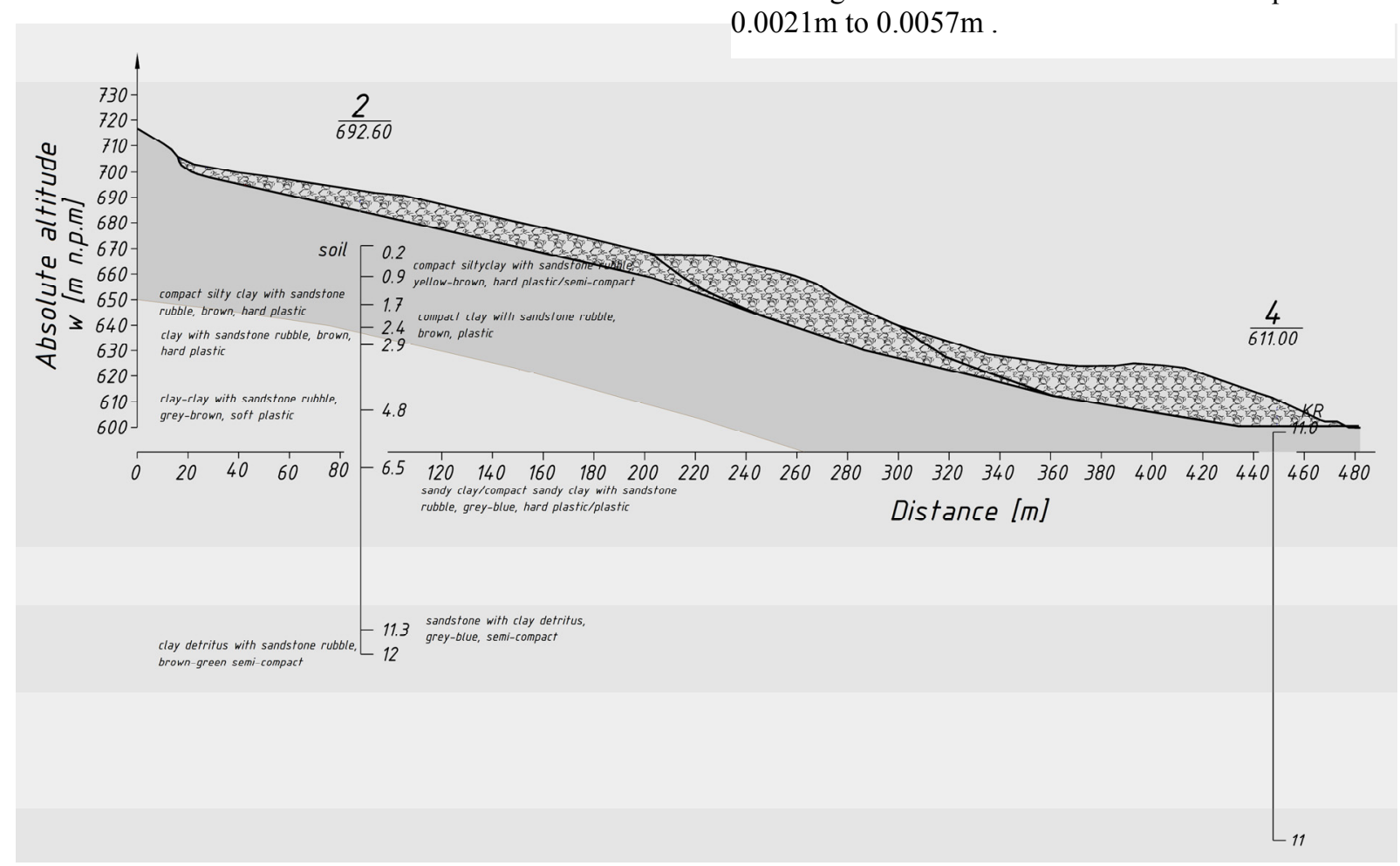

In the area of the landslide cartographic and geological works were done. In their framework three profile boreholes were made, 12 metres deep each (Szafarczyk, Rybicki et al, 2013). In the bottom part of the landslide, the samples for the laboratory analyses were taken from the research excavations in the colluviums formations.

In the landslide on the Prusów Mountain in Milówka the surfaces of structurally vulnerable parts were found in the whole studied profile, both in flysh and the overburden layers. The analysis of the results of field studies, drilling profiles and the results of laboratory studies show differentiated depth of the occurrence of slide surface. The most likely slide surface seems to be the zone of the contact of clay detritus with the layers of the Magura sandstones, occurring on the depth of about $4.3-7.3 \mathrm{~m}$ p.p.t in the upper part of the landslide to above $15 \mathrm{~m}$ p.p.t. in the lower part of the landslide (Fig. 2)

In the area of the landslide and its direct vicinity in September 2010, 74 points were stabilized. Their situation $\mathrm{X}, \mathrm{Y}, \mathrm{H}$ was determined in the cycles of 6 months over the period of 2 years and six months. The situation of 29 points was determined using GNSS technology in 40 minutes sessions in relation to the reference station ZYWI "ASG-EUPOS" system in Żywiec obtaining the maximal situation error equal from $0.0010 \mathrm{~m}$ to $0.0037 \mathrm{~m}$. The situation of 45 points was determined using linear and angular measurements (Szafarczyk, Rybicki et al., 2013) obtaining the maximal situation error equal from $0.0021 \mathrm{~m}$ to $0.0057 \mathrm{~m}$

Fig. 2 Geological and engineering cross-section through the landslide on the slope of Prusów in Milówka. 


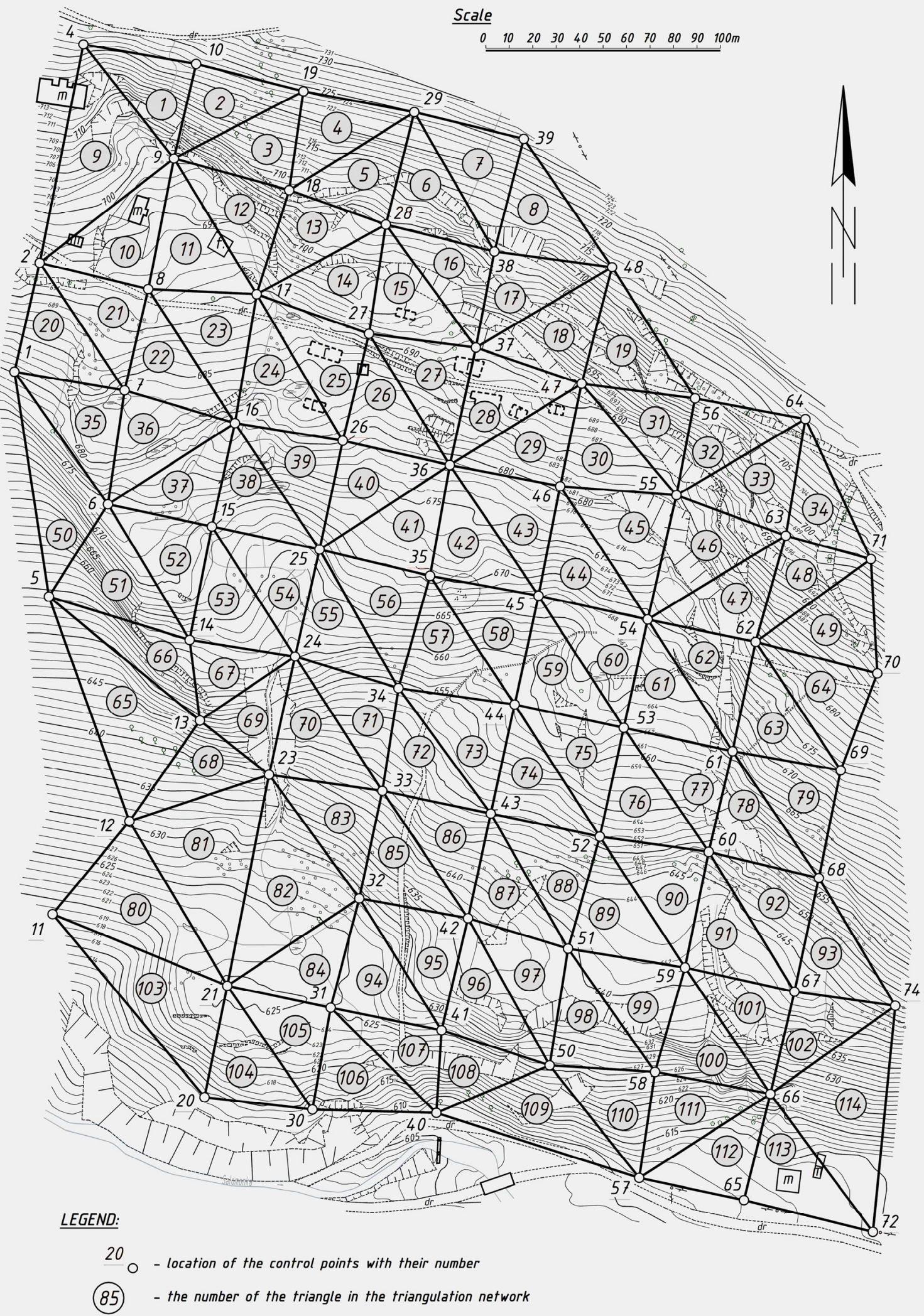

Fig. 3 The situation of measurement points on the background of the landslide in Milówka with the numbers of geodetic rosettes.

Consequently, 74 points made vertices for 114 triangular geodetic rosettes (Fig. 3). For these rosettes, for the period of 2 years and six months, the components of the strain tensor were marked, and from them - the values of extreme strains with the directions of their occurrence. The calculation results were presented in the form of vectors in a proper scale given in the legend (Fig. 4). 


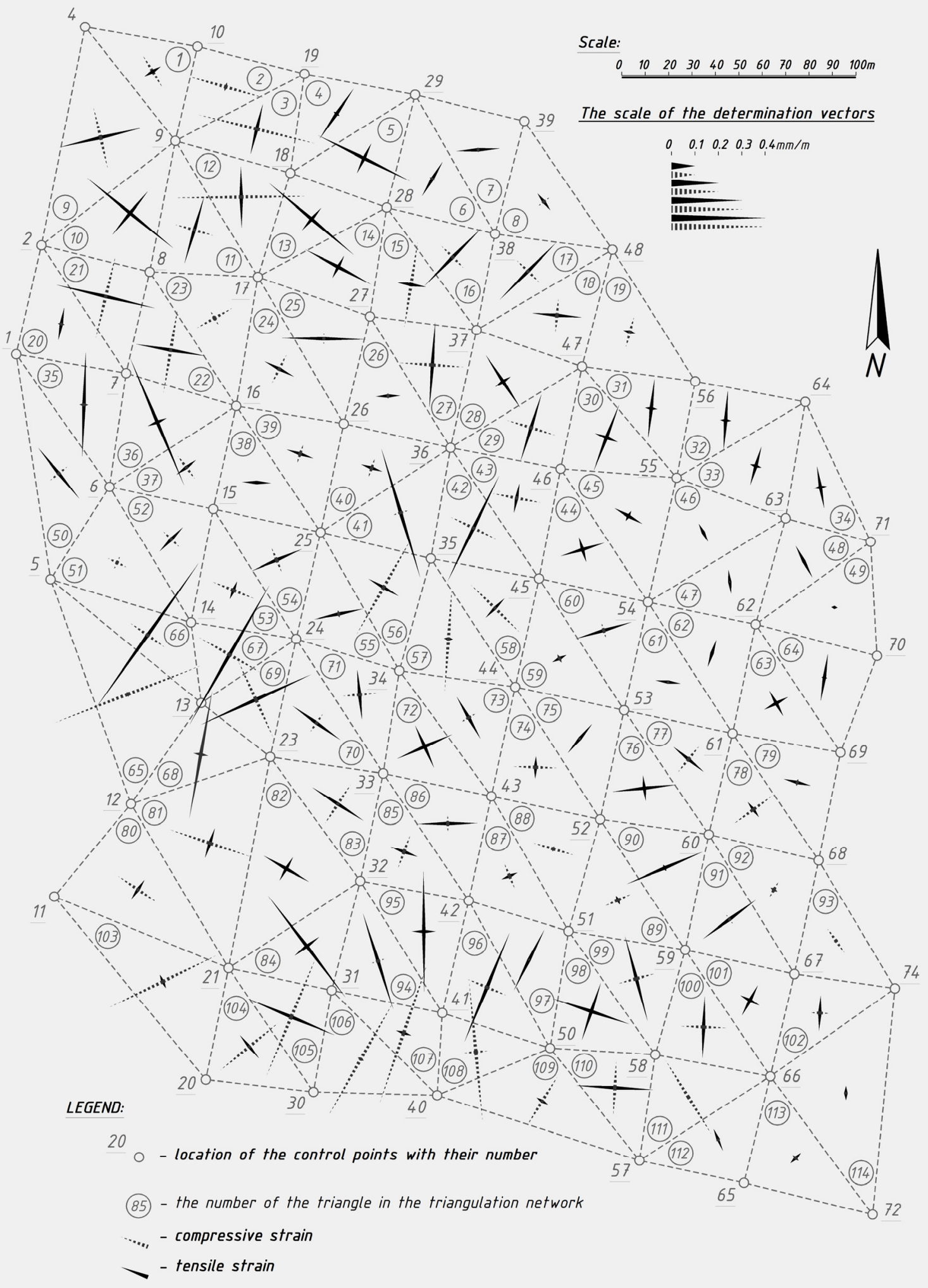

Fig. 4 Values of extreme strains marked for individual geodetic rosettes in the area of the landslide in Milówka. 
The calculated strains, both tensile and compressive do not exceed the value of $0.4 \mathrm{~mm} / \mathrm{m}$, which is a small value for the landslide, not causing damage to constructions located in the area of the landslide.

The accuracy of calculated strains ranges from $0.28 \mathrm{~mm} / \mathrm{m}$ to $1.27 \mathrm{~mm} / \mathrm{m}$ for several cases. It means that only part of strains were determined with an accuracy that is significant from a statistical point of view. This applied to areas located in the central part of the landslide, which was not covered by forest and allow better accuracy of coordinates measurement to be obtained.

The directions of the occurrence of tensile strains are much differentiated and indicate very high participation of a random factor (including the measurement error) in the obtained results. Taking into account the relief of the landslide, one can indicate regions, in which there are slow tensions, of the direction according to the direction of the slope inclination and the character of which is not accidental. These are regions: the landslide tongue (rosette: 84, 94, 95, 96, 97), niche in the central part of the landslide (rosette: 41,42 ) and niche in the western part of the landslide (rosette: 66, 67, 69). It is worth mentioning that in the direct vicinity of the regions of the mentioned rosettes, where tensile strains occur, in the southern direction (in the regions of lower altitude ordinates) tensions occur. This means that, in these regions, the material lying over the sliding layer accumulates making in the lower part of the landslide a tongue, and in the central part of the landslide of the scarp. The results of the carried out analyses indicate that in the mentioned areas very slow deformations still occur and the landslide has not settled down yet.

The most likely cause of the initiation of mass movements was the infiltration of precipitation waters leading to higher plasticity of Quaternary grounds. Taking into account the scale of atmospheric precipitation in 2010, the additional cause can also be the impact of spillways pressure and ground waters collected in permeable, cracked layers of sandstone on the upper, less permeable clay detritus.

\section{LANDSLIDE OF THE CONSTANT SLOPE OF THE OPEN CAST MINE „BELCHATÓW”}

The landslide marked as $24 \mathrm{~S}$, lying on a constant slope of the open cast mine of „Bełchatów” (Poland, Łódź voivodeship), was formed as a result of the carried out open cast mining. The landscape became visible in 2004, four months after the formation of the scarp in the quarry. The landslide at the beginning covered the interval of ordinates on the slope $+173 \mathrm{~m}$ a.s.l. to $147 \mathrm{~m}$ a.s.l., and then expanded taking the range of ordinates from about $+199 \mathrm{~m}$ a.s.l. to about $+120 \mathrm{~m}$ a.s.l. The morphometric parameters of the landslide were presented in Table 2.

Geological and engineering conditions of the slope were defined mainly based on archive studies (boreholes, charting the slope), as a part of our own studies, including ground-penetrating radar studied (Szafarczyk, Rybicki et al., 2013). These studies show that the slope in the zone of the formation of landslide $24 \mathrm{~S}$ is built mainly of tertiary formations and to smaller extent - from the Quaternary formations. Geological structure of the slope in the axis of the landslide $24 \mathrm{~S}$ is illustrated by the crosssection (Fig. 5).

Table 2 The morphometric parameters of the landslide 24S in Bełchatów.

\begin{tabular}{lc}
\hline Parameter & Value \\
\hline Area [ha] & 24 \\
Length [m] & 580 \\
Width [m] & 594 \\
Maximum height [m above sea level] & 199 \\
Minimum height & 120 \\
[m above sea level] & \\
Inclination $\left[{ }^{\circ}\right.$ ] & 16 \\
Azimuth $\left[{ }^{\circ}\right]$ & 350 \\
\hline
\end{tabular}

From the scarp of the slope five green loam samples were taken. Physical and mechanical parameters in the initial period of the development of landslide deformation were defined for these samples. The studies (Szafarczyk, Rybicki et al., 2013) show that green loams within the sand-loam Tertiary series made the landslide slide surface, which was also confirmed by deep measurements with an inclinometer situated almost in the axis of the landslide on the slope level $+174 \mathrm{~m}$ a.s.l.

In the area of the landslide and its direct vicinity there are 20 points stabilized (Fig. 6), the situation X, $\mathrm{Y}, \mathrm{H}$ of which is determined in the cycles 7-10 days with RTK GPS technology by the staff of the Surveying Division of the Mine. The measurement of each point is realised in two sessions RTK GPS in relation to the reference station located in the vicinity of the outcrop (the stability of which is controlled by leveling measure) collecting ten values of coordinates assuming the maximum difference between the average of two sessions equal to $2.5 \mathrm{~cm}$. The situation of 20 points is determined by obtaining the maximal situation error equal from $0.008 \mathrm{~m}$ to $0.014 \mathrm{~m}$.

The stabilized points were used in making the network of nineteen triangles making a triangular rosette (Fig. 6), for which like for the landslide in Milówka the components of the strain tensor were determined, the value of extreme strains and the directions of their occurrence. The above resultants were presented in a graphical form (Fig. 7).

Strains determined for this landslide for the studied period of time, i.e. from July 2010 to January 2013 reach the value of $20 \mathrm{~mm} / \mathrm{m}$, which is the value not allowing safe and reliable maintenance of any building, and moreover, posing threat to the workers of the mine and the machines working on the bottom of the excavation. 


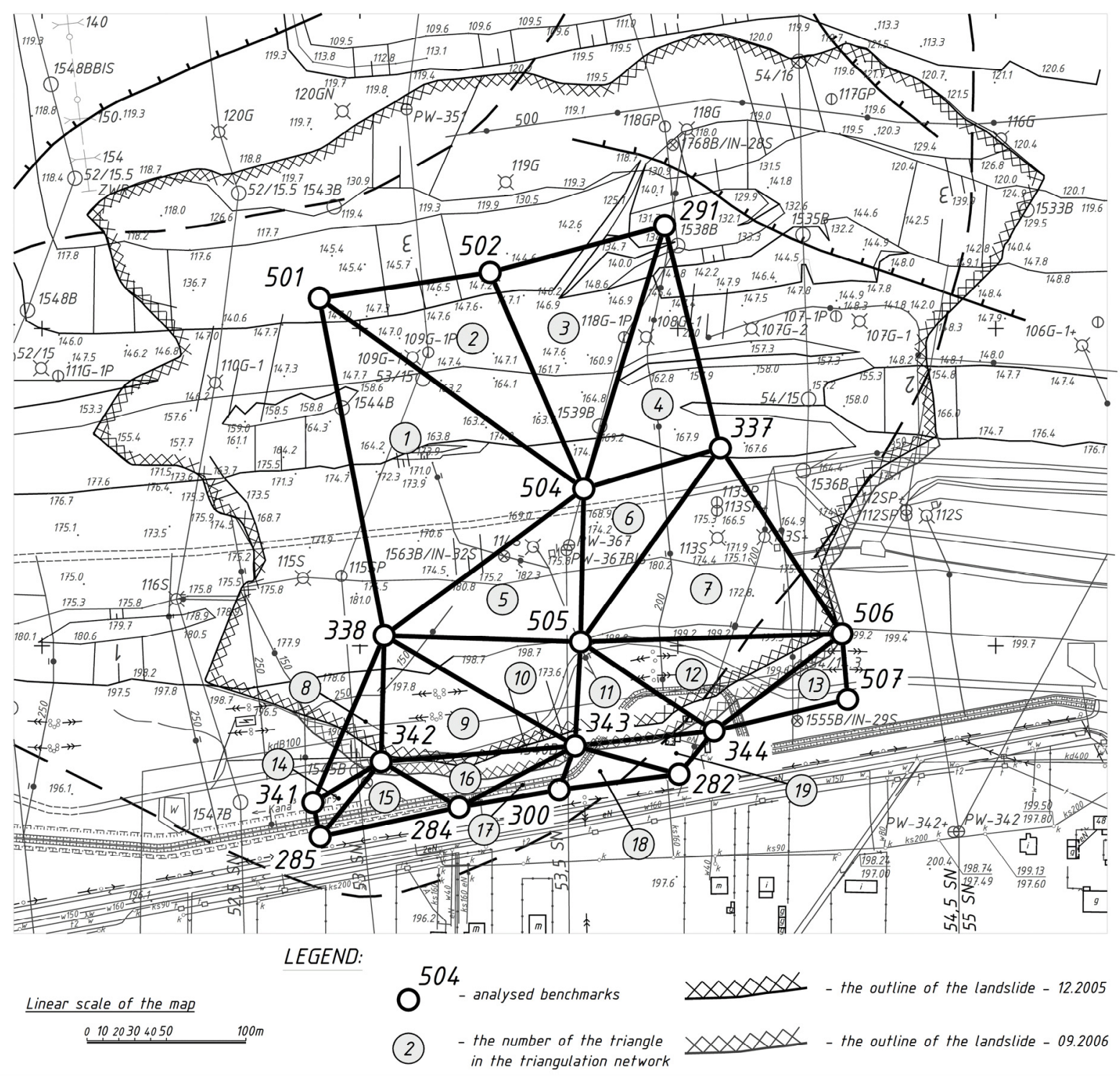

Fig. 6 The situation of measurement points on the background of landslide $24 \mathrm{~S}$ in Bełchatów with the numbering of geodetic rosettes.

The accuracy of calculated strains ranges from $0.15 \mathrm{~mm} / \mathrm{m}$ to $4 \mathrm{~mm} / \mathrm{m}$. According to obtained values of strains it means that all of them are significant from the statistical point of view.

All the determined tensile strains, apart from rosette number 16 , occur to the direction according to the direction of the inclination of the landslide, while their biggest values occur in the area of the main scarp (rosettes: 17, 18).

Strains compressive in the region rosette 16 indicate the fact of horizontal dislocations of point 284 down the slope (in the northern direction) of the values bigger than dislocation points 342, and 343, which proves continuous change of the landslide's outline. The main scarp in this area changes its situation due to a very big activity of landslide and „,moves" in the south direction posing direct threat for the energy network and the road.

\section{THE NOTES REFERRING TO THE APPLICATION OF ROSETTES}

The studies carried out earlier (Kontny et al., 2014; Szafarczyk et al., 2013; Talich, 2007; Cai, 2001) confirm that the constructions called rosettes are successfully applied to determine the state of strains in large areas (rosette sides of lengths of several dozen kilometres), as well as locally (sides about 20 metres). The selection of the localization of the established sides of rosettes or the use of already existing points, has a fundamental significance for a proper interpretation of the phenomenon and obtaining results according to actually occurring state of deformation. According to the studies carried out by Szafarczyk (2013) the assumption accepted in geodetic studies of strains, and referring to homogeneity of the ground medium is not fulfilled. This often results in getting different values of linear 


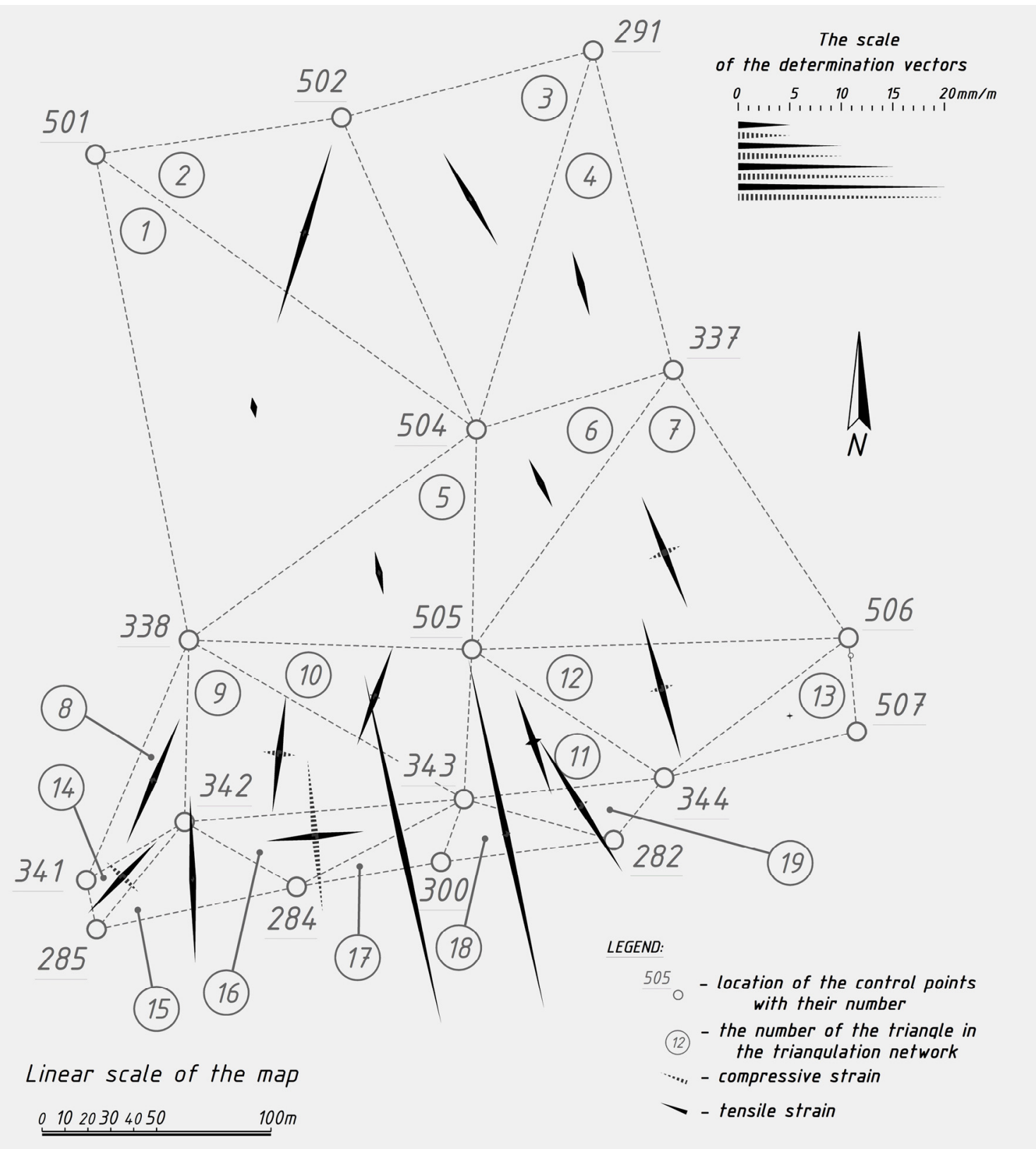

Fig. 7 The values of the extreme strains determined for individual geodetic rosettes in the area of landslide $24 \mathrm{~S}$ in Bełchatów.

strains in the same direction at the application of the different length of measurement sections.

In the presented two examples the attention was paid on the fact that the direction of the occurring extreme tensile strains not always is compliant with the direction of the greatest slope. The fact that the direction of the occurrence of extreme strains is the same by the whole period of the landslide process (also the duration of the measurements on the landslide) is not a result of a high precision of the measurements or the regularity of the process, but is connected with the situation of the rosette towards the source the occurring deformation. The presented method of determining the value of extreme strains is particularly useful in such regions, where the directions of extreme strains change in time. Thus it is useful to situate rosettes in the direct vicinity of threatened buildings, because it allows us to establish in the damage to the building were the effect of the activities of landslide or they are the result of possible construction failures of the object.

One should not limit the information to the value of strains, but it should always be supplemented by the information referring to the accuracy of the calculations. Depending on the applied way of length measurement, the same strain value might be or 
might not be significant from the statistical point of view. In case of the occurrence of significant strains causing damage to buildings, the cracks to the ground and/or discontinuous deformations, the lengths determined from the coordinates can be used in the analyses of the values. In case of slow strains, of small values one can apply direct measurement of the length of sections, for which strains are determined.

\section{ACKNOWLEDGEMENT}

The article was financed in the framework of the grant Badania Statutowe of the Department of the Protection of Mining Areas, Geoinformation and Mine Surveying, AGH-UST no. 11.11.150.195.

\section{REFERENCES}

Barber, I. S.: 2002, Elasticity. Kluwer, Dordrecht, 534 pp.

Cai, J.: 2001, Hypothesis test and sampling statistics of the eigenvalues and eigendirections of a random tensor of type deformation tensor. Report of DFG - Project GR 323/36-1 - Geodätisches Instytut Universität Stuttgart, Lehrstuhl Statistik Universität, Dortmund.

Cruden, D.M. and Varnes, D.J.: 1996, Landslide types and processes. In Special Report 247: Landslides: Investigation and Mitigation, Transportation Research Board, Washington D.C.

Ćmielewski, B., Kontny, B. and Ćmielewski, K.: 2013, Use of low-cost MEMS technology in early warning system against landslide threats. Acta Geodyn. Geomater., 10, No. 4 (172), 485-490. DOI: 10.13168/AGG.2013.0049

Dong, J. and Lee, W., Lin, M., Huang, A. and Lee, Y.: 2009, Effects of seismic anisotropy and geological characteristics on the kinematics of the neighboring Jiufengershan and Hungtsaiping landslides during Chi-Chi earthquake. Tectonophysics, 466, No. 3-4, 438-457. DOI: $10.1016 / j$.tecto.2007.11.008

Gili, J.A., Corominas, J. and Rius, J.: 2000, Using Global Positioning System techniques in landslide monitoring. Engineering Geology, 55, No. 3, 167192. DOI: $10.1016 / \mathrm{S} 0013-7952(99) 00127-1$

Hejmanowski, R.: 2005, Optimization of determining horizontal surface deformations for the protection of buildings in mining areas. Report of Research Project 5T 12E 04124, Akademia Górniczo-Hutnicza, Kraków, (in Polish).

Hill, R.: 1950, The matematical theory of plasticity. Clarendon Press, Oxford, 366 pp.

Hjelmstad, K.D.: 2005, Fundamentals of structural mechanics. Springer, Berlin, 783 pp.

Kontny, B., Grzempowski, P., Aleksandrowski, P., Schenk, V. and Schenková, Z.: 2014, Horizontal deformation of the Earth's crust in the area of Sudeten and its northern foreland (SW Poland) based on GPS data from the period 1997-2012. In: $15^{\text {th }}$ Czech-Polish Workshop "On Recent Geodynamics of the Sudeten and Adjacent Areas", Karlov pod Pradědem, Czech Republic, November 5-8. Abstracts, 40-41.

Kostić, S., Vasović, N., Franović, I., Jevremović, D., Mitrinovic, D. and Todorović, K.: 2014, Dynamics of landslide model with time delay and periodic parameter perturbations. Communications in
Nonlinear Science and Numerical Simulation, 19, No. 9, 3346-3361.

DOI: $10.1016 /$ j.cnsns.2014.02.012

Kwinta, A.: 2012, Prediction of strain in a shaft caused by underground mining. International Journal of Rock Mechanics and Mining Sciences, 55, 28-32.

DOI: $10.1016 /$ j.ijrmms.2012.06.007

Lebedev, L.P., Cloud, M.J. and Eremeyev, V.A.: 2010, Tensor analysis with applications in mechanics. World Scientific, Singapore, 363 pp.

Lenda, G., Ligas, M., Lewińska, P. and Szafarczyk, A.: 2016, The use of surface interpolation methods for landslides monitoring, KSCE Journal of Civil Engineering, 20, No. 1, 188-196. DOI: $10.1007 / \mathrm{s} 12205-015-0038-4$

McColl, S.T.: 2015, Landslide causes and triggers, landslide hazads, risk and disasters. Chapter 2, 17-42. DOI:10.1016/B978-0-12-396452-6.00002-1

Okamoto, T., Larsen, J. O., Matsuura, S., Asano, S., Takeuchi, Y. and Grande, L.: 2004, Displacement properties of landslide masses at the initiation of failure in quick clay deposits and the effects of meteorological and hydrological factors. Engineering Geology, 72, No. 3-4, 233-251. DOI: $10.1016 /$ j.enggeo.2003.09.004

Pavlov, A.P.: 1968, Landslide general classifications. Engineering geology reference book. "Nedra" Publishers, Moscow, $181 \mathrm{pp}$.

Pielok, J. and Szafarczyk, A.: 2004, Geodetic measurements of surface deformations with the use of tensometry methods. Das Markscheidewesen, 111, nr 3, 98-103.

Prokešová, R., Kardoš, M. and Medved'ová, A.: 2010, Landslide dynamics from high-resolution aerial photographs: A case study from the Western Carpathians, Slovakia. Geomorphology, 115, Nos. 12, 90-101. DOI: 10.1016/j.geomorph.2009.09.033

Ramesh, M.V.: 2014, Design, development, and deployment of a wireless sensor network for detection of landslides. Ad Hoc Networks, 113, Part A, 2-18. DOI: 10.1016/j.adhoc.2012.09.002

Savarensky, F.P.:1981, Landslides, landslides classification. Engineering geology reference book. "Nedra" Publishers, Moscow, 87-88.

Sharpe, C.F.: 1938, Landslides and related phenomena. New York: Columbia University Press, $1370 \mathrm{pp}$.

Sokolnikoff, I.S.: 1946, Mathematical theory of elasticity. Mc Graw-Hill, New York, 373 pp.

Stumpf, A., Malet, J.F., Kerle, N., Niethammer, U. and Rothmund, S.: 2013, Image-based mapping of surface fissures for the investigation of landslide dynamics. Geomorphology, 186, 12-27. DOI: 10.1016/j.geomorph.2012.12.010

Szafarczyk, A.: 2013, Determination of horizontal deformations of the mining area using geodetic rosettes. Wydawnictwa AGH, 144, (in Polish).

Szafarczyk, A., Rybicki S. et al: 2013, Study of the kinematics of surface mass movements using groundbased radar interferometry. Wydawnictwa AGH, 126 pp., (in Polish).

Talich, M.: 2007, Geometrical analysis of deformation measurement using continuum mechanics by web application. In: Strategic Integration of Surveying Services, The XXX FIG General Assembly and Working Week 2007, Hong Kong SAR, China, 13-17 May 2007. 
Teza, G., Pesci, A., Rinaldo, G. and Galgaro, A.: 2008, Characterization of landslide ground surface kinematics from terrestrial laser scanning and strain field computation. Geomorphology, 97, Nos. 3-4, 424-437. DOI: 10.1016/j.geomorph.2007.09.003

Varnes, D.J.: 1978, Slope movement types and processes. In Special report 176: Landslides: Analysis and Control, Transportation Research Board, Washington, D.C.

Wang, K.L. and Lin, M.L.: 2011, Initiation and displacement of landslide induced by earthquake a study of shaking table model slope test. Engineering Geology, 122, No. 1-2, 106-114.

DOI: $10.1016 /$ j.enggeo.2011.04.008

Wasowski, J. and Bovenga, B.: 2015, Remote sensing of landslide motion with emphasis on satellite multitemporal interferometry applications: An overview, landslide hazards, risks and disasters. Chapter 11, 345-403.

DOI: 10.1016/B978-0-12-396452-6.00011-2

Yenes, M., Monterrubio, S., Nespereira, J. and Santosc, G.: 2009, Geometry and kinematics of a landslide surface in tertiary clays from the Duero Basin (Spain). Engineering Geology, 104, Nos. 1-2, 41-54.

DOI: 10.1016/j.enggeo.2008.08.008

Zhu, Z.W., Liu, D.Y., Yuan, Q.Y., Liu, B. and Liu, J.C.: 2011, A novel distributed optic fiber transduser for landslides monitoring. Optics and Lasers in Engineering, 49, No. 7, 1019-1024.

DOI: 10.1016/j.optlaseng.2011.01.010 